\title{
NiHiliStic Dentistry
}

\author{
PeterWard \\ Chief Executive, BDA
}

The BDJ Upfront section includes editorials, letters, news, book reviews and interviews. Please direct your correspondence to the News Editor,

Kate Quinlan at BDJNews@nature.com. Press releases or articles may be edited, and should include a colour photograph if possible.

A pril Fools' Day this year will mark the eleventh anniversary of the imposition of the 'new' NHS GDS contract in England. Following early attempts to justify and legitimise their invention, officials within the NHS and Department of Health were eventually forced to admit that their unit of contract currency was intrinsically destructive and unfair. Government Ministers are on record saying that the system was unacceptable and in need of change. Mindful, however, of the way in which the 2006 contract had been bludgeoned in, officials set out a course for more measured and better informed change. There were to be pilots, and then prototypes, and the implementation of change by 2015 .

A combination of local and wider national issues conspired to derail that timeline and now the hope of substantive change becomes mirage-like as it glimmers just round the next corner. The delays and regroupings are legion and one does begin to wonder whether the government's heart is in it after all. It looks very much as if, despite recognising the failings of this system, NHS officials are really content with the status quo. If that were the case, every day that it persists represents a successful day for the government team.

If you wonder why the officials might hold that opinion, just look at the 'free' dentistry they are getting under the current system. Last year, approximately $£ 15$ million worth of dentistry was delivered by dentists over-performing their $100 \%$ contract quantum. The bulk of this work attracted no credit to the dentists themselves. The clinical interventions provided at no cost to government. Indeed, the insult to injury was that where charges were either paid or owed by patients, equivalent sums were deducted from the other fees earned by dentists. And, in circumstances where the patients failed to pay, the dentists actually paid for the privilege of providing the dentistry.

Multiply that $£ 15$ million over the eleven years of the contract and conservatively you can estimate that NHS England as it now is has benefitted from at least $£ 165$ million of free dentistry. Anyone benefitting at someone else's expense might be slow or reluctant to bring about change that would deny them that benefit.

Much has already been said about the ridiculous expectations attached to UDAs by way of limitless amounts of treatment for the same fee. But the vindictive and controlling words in the GDS/PDS Regulations (2005) provide the double whammy. By this I mean that it isn't just the expectations of quantity that are unlimited, it is the quality as well. The obligation that the contractor 'must provide to its patients all proper and necessary dental care and treatment' penalises any dentist who chooses to enhance their skills and invest in perverse consequences. If this interpretation is really true, dentists would be well advised not to invest in themselves or their offerings if they work within the NHS. If you don't know about something or haven't the wherewithal to offer it, you don't have to do it. Once you have paid for the skills and equipment at your own expense you must then do the higher quality treatment at the bargain basement price. And not only that, you must do as many 'its' as the patient requires all for a single fee.

If the raw bones of the deal are harsh, the addition of voracious commissioners looking for new and interesting ways to bar claims and claw back money make this a really unpleasant environment in which to work. If the other party to this were a commercial player or a slum landlord, these tricks would

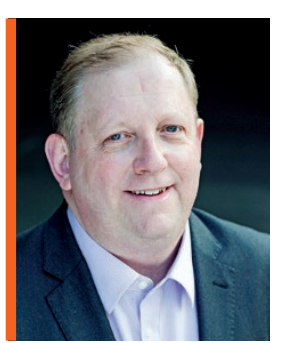
\section{'...NHS England has} benefitted from at least $£ 165$ million of free dentistry... new kit. This stems from the interpretation that whatever 'it' is, if the patient needs it and you can do it then you have to do it at an NHS fee rate. Conscientious practitioners do want to enhance their skills, they do want to buy better equipment and better quality materials.

Even more pernicious is the requirement when mixing NHS and private care not to mislead the patient about the availability of that treatment on the NHS or about the respective quality of the services. Every day, GDPs walk this tightrope, balancing an honest, open discussion with their patients about the treatment options against the gnawing fear of a complaint or scrutiny of the GDC. The suggestion that the offer of private alternatives is unacceptable has quite be condemned as unfair and unacceptable. But the other party is, of course, the agent of Her Majesty's Government.

The flaws and conflicts in this contract were identified very quickly after its introduction and despite the protestations of its designers. The need for change was vocally articulated by Ministers at least seven years ago. The inequities get worse by the day and yet the backsliding and delay of reform continues. GDPC negotiators seek to feed in constructive amendments but the pace of the change process is glacial.

And every day the English Department of Health benefits to the tune of $£ 41,000$ worth of free dentistry. I wonder why it's taking so long? -

DOI: 10.1038/sj.bdj.2017.244 